\title{
Preparation and Characterization of Bioactive Chitosan-Based Films Incorporated with Olive Leaves Extract for Food Packaging Applications
}

\author{
Enrica Musella ${ }^{1,2}$, Ismael Chahed el Ouazzani ${ }^{1,3}$, Ana Rita Mendes ${ }^{3}$, Cesare Rovera ${ }^{2}\left(\mathbb{D}\right.$, Stefano Farris ${ }^{2, *} \mathbb{D}$, \\ Cristina Mena ${ }^{1}$, Paula Teixeira ${ }^{3}$ (D) and Fátima Poças ${ }^{1,3, *}$ \\ 1 Universidade Católica Portuguesa, CINATE, Escola Superior de Biotecnologia, 4169-005 Porto, Portugal; \\ enri.musella8@gmail.com (E.M.); ismael.ouazzani@gmail.com (I.C.e.O.); cmena@ucp.pt (C.M.) \\ 2 Food Packaging Lab., DeFENS, Department of Food, Environmental and Nutritional Sciences, \\ University of Milan, via Celoria 2-I, 20133 Milan, Italy; cesare.rovera@unimi.it \\ 3 Universidade Católica Portuguesa, $\mathrm{CBQF}$-Centro de Biotecnologia e Química Fina-Laboratório Associado, \\ Escola Superior de Biotecnologia, Rua Diogo Botelho 1327, 4169-005 Porto, Portugal; \\ ritamatosmendes@gmail.com (A.R.M.); pcteixeira@ucp.pt (P.T.) \\ * Correspondence: stefano.farris@unimi.it (S.F.); fpocas@ucp.pt (F.P.)
}

\section{check for}

updates

Citation: Musella, E.; Ouazzani, I.C.e.; Mendes, A.R.; Rovera, C.; Farris, S.; Mena, C.; Teixeira, P.; Poças,

F. Preparation and Characterization of Bioactive Chitosan-Based Films Incorporated with Olive Leaves Extract for Food Packaging Applications. Coatings 2021, 11, 1339. https://doi.org/10.3390/

coatings11111339

Academic Editor: Andrzej Lenart

Received: 18 August 2021

Accepted: 29 October 2021

Published: 31 October 202

Publisher's Note: MDPI stays neutral with regard to jurisdictional claims in published maps and institutional affiliations.

Copyright: (c) 2021 by the authors. Licensee MDPI, Basel, Switzerland. This article is an open access article distributed under the terms and conditions of the Creative Commons Attribution (CC BY) license (https:// creativecommons.org/licenses/by/ $4.0 /)$

\begin{abstract}
Chitosan films with olive leaf extract (OLE) incorporated at different concentrations were characterized regarding their antimicrobial, antioxidant and some relevant physical properties (i.e., solubility, water vapor permeability, and tensile properties). Results indicate that the active films have substantial antimicrobial activity against Listeria monocytogenes and Campylobacter jejuni mostly extending the microorganisms lag phase. A lower level of inhibition was found in the case of Escherichia coli. However, the OLE seems not to improve the intrinsic antimicrobial properties of the chitosan itself, except for $C$. jejuni. These results were confirmed with in situ testing using chicken. The chitosan films with OLE exhibited antioxidant activity, increasing with the OLE concentration, from 0.04 to $0.15 \mathrm{~g} / \mathrm{L}$ ascorbic acid equivalents, corresponding to films with $10 \%-30 \%$ OLE relative to the chitosan. Chitosan films loaded with OLE exhibited a higher solubility in food simulants and a reduced permeability against water vapor. Overall, the combination of OLE and chitosan allows to obtain a promising active bio-based packaging solution for addressing safety and quality issues.
\end{abstract}

Keywords: active packaging; antimicrobial; antioxidant; oleuropein; safety; shelf life

\section{Introduction}

Food loss and food waste, besides representing an economic and a societal issue, are a major problem today because of the high impact that they might have on the environment [1]. Although different causes can contribute to food losses and food waste (from harvest to consumption), microbiological contamination accounts for up to $25 \%$ of the waste of fresh, highly perishable food prior to consumption [2]. Currently, more than 250 different foodborne hazards have been identified including those from microbial agents, toxins and chemicals that are able to contaminate food products during cultivation, processing, packaging, and distribution. Among others, the main pathogens that are widely recognized to pose a serious risk to the consumers' health are Salmonella spp., Campylobacter spp., Listeria monocytogenes, and Escherichia coli [3,4]. Therefore, due to health risks, economic losses, and environmental impact, food industries are increasingly looking for new technologies and processes that guarantee safety, high quality, and longer shelf life of food products.

Food packaging includes a number of technologies that allow preserving the food over time, controlling the quality decay and microbial spoilage. Modified atmosphere packaging (MAP), vacuum packaging, and oxygen barrier materials are just a few examples of the available strategies to extend the shelf life of perishable foods. More recently, active 
packaging proved to be an efficient and feasible strategy that can be integrated with conventional approaches for achieving an extra performance of the whole package [5]. Active packaging can be profitably used to protect the food against factors of degradation such as oxidation, moisture uptake, accelerated ripening, and microbial spoilage, while reducing the amount of preservatives directly added into the food [6]. According to the EU legislation [7], active packaging can be defined as a packaging system that is able to interact with the food and with the environment surrounding the food by absorbing or releasing substances from or into the food. In turn, these mechanisms aim to enhance the safety or sensory properties of the food product, while maintaining its quality and extending its shelf life [8]. The use of active packaging systems seems to meet the increasing attention of consumers for fresh and healthy foods. In addition, the increasing use of polymers of renewable origin instead of oil-based plastics makes these systems more appealing for a sector increasingly looking for environmentally sustainable solutions [9].

Currently, biopolymers of polysaccharides, proteins, and lipids have been successfully used to obtain active packaging systems in the form of coatings directly applied on the food's surface or on the inner side of the packaging materials [10]. Chitosan, in particular, has been extensively used because of availability and biodegradability [11]. Chitosan is a polysaccharide that can be extracted from the shell of crustaceans, materials normally wasted by the fishery industry. One of the main advantages of chitosan over other biopolymers is its inherent antimicrobial activity, which makes chitosan the first-choice biopolymer for the development of antimicrobial active packaging systems [12]. The antimicrobial activity of chitosan has been attributed to four main factors: (i) the interaction between the positively charged amino groups of chitosan with the negatively charged cell wall, which leads to cell surface distortions/breakages and cellular material loss; (ii) the chelating properties of chitosan, which are reflected in the inhibition of the enzymatic activity of the cell; (iii) for high molecular weight chitosan, the capability to envelop the cell changing its permeability until the entrance of nutrients is blocked; (iv) chitosan with lower molecular weight can penetrate inside the cell and bind the DNA, decreasing the efficiency of the mRNA and proteins synthesis mechanisms until the cell's death [12-14]. The effectiveness of chitosan films and coatings against microbial spoilage strongly depends on some specific aspects, such as the target microbial species, intrinsic factors such as the chitosan molecular weight or the acetylation degree, the physical state of the chitosan and on environmental parameters such as $\mathrm{pH}$ value and temperature [15].

In most applications, chitosan films and coatings have been combined with active molecules in order to broaden the antimicrobial spectrum of the final packaging material while adding new active features, such as the antioxidant property [16]. Moreover, the addition of small molecules may be beneficial to improve some inherent drawbacks of chitosan films and coatings, such as brittleness and high sensitivity to moisture. In this respect, one of the most successful combination of chitosan is with essential oils and plant extracts [17]. For example, chitosan has been used in combination with oregano oil [9], clove oil [18], ginger oil [19], tea polyphenols [20], rosmarinic acid [21], pomegranate peel extract [22], and peptides extracted from soy, corn and caseins [23] for the generation of active films tested on different food matrices, such as meat or vegetables.

Olive leaf extract (OLE) is one of the highest value by-products arising from the olive oil industry. It is a dark-brown liquid with a bitter taste and a high percentage of active compounds belonging to secoiridoids, hydroxytyrosol, polyphenols, triterpenes, and flavonoids in different concentrations depending on both cultivar and environmental conditions [24]. Oleuropein, in particular, is a secoiridoid, more specifically the heterosidic ester of elenolic acid and hydroxytyrosol, found in the olive skin, seeds, oil and especially leaves [25]. Oleuropein is referred to as the main compound responsible for the OLE properties, especially strong antioxidant and antimicrobial activities [26].

This work has focused on the combination of chitosan with OLE for the development of active coatings with both antimicrobial and antioxidant properties. A preliminary characterization of the active properties of the films was followed by in situ specific tests using 
chicken breast, demonstrating the validity of this approach for the development of active biopolymer films as an alternative to conventional plastics for shelf-life extension purposes.

\section{Materials and Methods}

\subsection{Materials and Chemicals}

Medium molecular weight (190,000-310,000 g/mol) chitosan (CH) with 75\%-85\% deacetylation degree (DD) was purchased from Sigma Aldrich (Shanghai, China). Glycerol p.a. (GLY, 87\%) was purchased from Pronolab (Lisboa, Portugal), while olive leaves extract (OLE) with $15 \%$ of oleuropein (Olea Europea L.) was purchased from Infinite Choice (Coimbra, Portugal). Oleuropein (96\%, HPLC grade) from Merck KGaA (Darmstadt, Germany) was used as standard. Hydrochloric acid (37\%) and sodium hydroxide (anhydrous pellets) were purchased from Merck KGaA. Sodium persulfate $\left(\mathrm{K}_{2} \mathrm{~S}_{2} \mathrm{O}_{8}\right)$ and 2,2'-azinobis (3-ethylbenzothiazoline-6-sulfonic acid) (ABTS) were purchased from SigmaAldrich (Saint Louis, MO, USA). Escherichia coli (ATCC ${ }^{\circledR} 8739^{\mathrm{TM}}$ ), Listeria monocytogenes (LM 2542, ESB culture collection) and Campylobacter jejuni subsp. jejuni (ATCC 33560) were the microorganisms used in this study. Bacteria were grown in the following media: tryptone soy broth (TSB) for E. coli $\left(37^{\circ} \mathrm{C}\right)$, modified charcoal-cefoperazone-deoxycholate agar (mCCDA) for C. jejuni $\left(41.5^{\circ} \mathrm{C}\right)$ and Agar Listeria acc. to Ottaviani \& Agosti (ALOA $\left.{ }^{\circledR}\right)$ for L. monocytogenes $\left(37^{\circ} \mathrm{C}\right)$. Distilled water was used throughout the experiments.

\subsection{Preparation of Chitosan and Chitosan-Olive Leaf Extract Films}

Chitosan films were obtained according to the methods proposed by Yingyuad et al. [27] and Peng et al. [28]. Briefly, a CH water solution $(2 \% w / v)$ was prepared by dissolving $\mathrm{CH}$ powder in acidic water $\left(1 \% v / v\right.$ glacial acetic acid) at $50 \pm 0.5{ }^{\circ} \mathrm{C}$ under gentle stirring until complete dissolution. Glycerol was then added $(30 \% w / w)$ to the $\mathrm{CH}$ solution as a plasticizer. The solution was homogenized for $1 \mathrm{~h}$ at room temperature using a magnetic multi-stirrer (Velp Scientifica, Italy). When necessary, OLE was added to the CH-GLY solution according to the method proposed by Ashrafi et al. [8]. In particular, three different OLE concentrations $(10 \%, 20 \%$, and $30 \% w / w$, relative to the chitosan mass) were added to the $\mathrm{CH}-\mathrm{GLY}$ solution, which was then stirred at $50 \pm 0.5^{\circ} \mathrm{C}$ until complete homogenization. Aliquots $(25 \mathrm{~mL})$ of the $\mathrm{CH}$-based solutions were poured into glassy Petri dishes $(\varnothing=9 \mathrm{~cm})$, which were then left to dry for $48 \mathrm{~h}$ at $40^{\circ} \mathrm{C}$. After drying, dishes were allowed to rest for additional $24 \mathrm{~h}$ at room temperature, after which $\mathrm{CH}-\mathrm{GLY}$ films were peeled off and placed in a desiccator before analyses. Films with thickness of $113 \mu \mathrm{m}$ in average were obtained.

\subsection{Analyses}

\subsubsection{OLE and Chitosan Characterization}

The concentration of oleuropein in OLE was determined by high-performance liquid chromatography (HPLC) according to the method reported by Szymanski et al. [29]. To this scope, a Gold Liquid Chromatograph (Beckman Coulter, Brea, CA, USA) was used with a UV-VIS/DAD detector operating at $254 \mathrm{~nm}$. The chromatographic separation was performed on a RP-18 Hypersil ODS column $(5 \mu \mathrm{m}$, length $250 \mathrm{~mm}$, i.d. $4.6 \mathrm{~mm}$, MZ-Analysentechnik, Mainz, Germany). A mobile phase of acetonitrile $(200 \mathrm{~mL})$ /water $(800 \mathrm{~mL})$ was used with an isocratic flow rate of $1 \mathrm{~mL} / \mathrm{min}$. The calibration curve was obtained using standards solutions $(0.05,0.10,0.25,0.50,1.00$ and $1.50 \mathrm{mg} / \mathrm{mL})$ prepared by serial dilutions of a stock solution of the oleuropein standard in methanol $(5 \mathrm{mg} / \mathrm{mL})$. The HPLC method implemented showed good performance, namely: linearity up to $1.5 \mathrm{mg} / \mathrm{mL}$ (correlation coefficient of 0.999 ), limits of detection and quantification, respectively 0.03 and $0.12 \mathrm{mg} / \mathrm{mL}$ and recovery between $85 \%$ and $120 \%$.

The DD of chitosan was determined in triplicate according to the titration method proposed by Czechowska-Biskup et al. [30]. Chitosan was dissolved in hydrochloric acid solution $0.1 \mathrm{M}$ under gentle stirring and homogenisation until complete dissolution. The 
solution was then titrated manually with sodium hydroxide $(0.1 \mathrm{M})$. The DD was finally calculated using the following Equation (1):

$$
D D[\%]=2.03 \times \frac{\mathrm{V} 2-\mathrm{V} 1}{\mathrm{~m}+0.0042 \times(\mathrm{V} 2-\mathrm{V} 1)}
$$

where $m$ is the weight of chitosan, V1 and V2 are the volumes sodium hydroxide solution corresponding to the deflection points of the titration curve, 2.03 is the coefficient resulting from the molecular weight of chitin monomer unit, and 0.0042 is the coefficient resulting from the difference between the molecular weights of chitin and chitosan monomer units.

\subsubsection{Evaluation of Active Properties}

Suspensions of L. monocytogenes, E. coli and C. jejuni were prepared in Ringer's solution from overnight cultures. Flasks with $50 \mathrm{~mL}$ of Trypto-Caseíne soy broth (TSB, Biokar, France) were inoculated with $1 \mathrm{~mL}$ of each bacterial suspension in order to have an initial level of microorganisms between $10^{6}-10^{7} / \mathrm{mL}$. Growth at $22 \pm 2{ }^{\circ} \mathrm{C}$ (room temperature) and at 37 and $41.5^{\circ} \mathrm{C}$ (optimal temperatures for the selected bacteria), was monitored measuring the optical density at $600 \mathrm{~nm}$ using a Multiskan Sky Microplate Spectrophotometer (Thermofisher Scientific, Waltham, MA, USA). Uninoculated TSB was used as blank.

The antimicrobial activity of the CH-based films was assessed according to the ASTM E2149 standard method for immobilized antimicrobial agents under dynamic contact conditions. Accordingly, three pieces of the CH-GLY and CH-GLY-OLE films (each piece with an area of $4 \mathrm{~cm}^{2}$, that is, a surface to volume ratio of $0.6 \mathrm{~cm}^{2} / \mathrm{mL}$ ) were immersed in $20 \mathrm{~mL}$ of TSB medium and the microbial growth monitored at both temperatures $(22,37$, and $41.5 \pm 0.5^{\circ} \mathrm{C}$ ) using the $\mathrm{OD}_{600}$ method as described previously. A flask without any film was also used as a blank. Flasks with films were prepared in duplicate and 3 runs were repeated in different days.

An in situ test was performed targeting the effect of OLE against $C$. jejuni where sterile agar with OLE at $2 \%$ concentration was brought in contact with inoculated chicken pieces. The OLE was homogeneously solubilized in the transparent medium and poured into plates.

Before inoculation, small pieces of chicken (approximately $2 \mathrm{~cm} \times 2 \mathrm{~cm} \times 1 \mathrm{~cm}$ ) were immersed in ethanol and allow to dry for $5 \mathrm{~min}$ for surface sterilization. Subsequently, they were brought in contact for $1 \mathrm{~min}$ (only one face) with a suspension of $C$. jejuni (turbidity equivalent to 0.5 in McFarland scale). Campylobacter spp. counts in the suspension were determined according to the ISO 10272-2:2017.

Three pieces of chicken were placed in each plate with $2 \%$ OLE. A negative control was also prepared with two pieces in an agar plate without OLE. The plates were stored in microaerophilia ( $5 \% \mathrm{CO}_{2} ;$ Heracell $\mathrm{CO}_{2}$ incubator, Heraeus, Germany) at $41.5^{\circ} \mathrm{C}$ for $48 \mathrm{~h}$ and at $4{ }^{\circ} \mathrm{C}$ for 4 days (GENbox microaer, bioMérieux, Marcy-l'Étoile, France). Campylobacter jejuni counts on the meat pieces were determined according to ISO 102722:2017 at the end of the incubation period and also at the beginning of the experiment in a control.

The antioxidant activity of $\mathrm{CH}$-based films was evaluated by means of the ABTS assay, according to the procedure described by Ozgen et al. [31]. Three pieces of the film with a surface area of $4 \mathrm{~cm}^{2}$ were immersed in $20 \mathrm{~mL}$ of deionized water. One $\mathrm{mL}$ amount of the $\mathrm{ABTS}^{++}$stock solution was filtered with a syringe filter and diluted with water until an absorbance of $0.700 \pm 0.02$ at $734 \mathrm{~nm}$ was obtained. Then, $10 \mu \mathrm{L}$ of the water in contact with the films were added to the $\mathrm{ABTS}^{++}$and the absorbance of the final solution was read (in dark, to avoid all possible interactions with light) after $6 \mathrm{~min}$. The results of the ABTS assay were expressed as ascorbic acid equivalent antioxidant capacity (AAEAC) using a calibration curve. The antioxidant activity was evaluated both on CH-GLY-OLE films with different concentration of OLE and on CH-GLY films without OLE. A blank (distilled water) was also prepared. 


\subsubsection{Physical Characteristics of the Films}

The films thickness was measured with an electronic gauge (Adamel-Lhomargy, Roissy-en-Brie, France). The average value of three thickness measurements per film was used in all calculations.

The interaction of films with foods was assessed by measuring the solubility into different aqueous solutions, simulating foods. It was determined as the percentage relative to the dry matter of the film solubilized at room temperature after $24 \mathrm{~h}$ immersion in water, acetic acid 3\% $(\mathrm{m} / \mathrm{v})$, ethanol 10,20 and $50 \%(v / v)$, according to the simulants foreseen in the European legislation applicable to plastic materials in contact with food (Commission Regulation (EU) No 10/2011). Each film was tested in replicate by immersion of disks of $1.5 \mathrm{~cm}$ diameter. The dry weight of the film (initial and after contact with the simulant) was determined by drying to constant weight in an oven at $105^{\circ} \mathrm{C}$.

The water vapour transmission rate (WVTR) of the films was determined by the gravimetric method (ISO 2528:1995). Metallic cups containing pre-dried calcium chloride $\left(\mathrm{CaCl}_{2}\right)$ anhydrous salt were sealed with the films and stored at $23 \pm 2{ }^{\circ} \mathrm{C}$ and $50 \% \pm 5 \%$ relative humidity. The increase of cup weight, resulting from water transfer through the sample, was monitored regularly. The WVTR was calculated with the slope of linear regression from the weight gain over time, in the constant rate period, normalized by the film exposed area. The difference of partial vapour pressure between the two faces of the films was $1406 \mathrm{~Pa}\left(50 \%\right.$ relative humidity and saturation vapour pressure at $23{ }^{\circ} \mathrm{C}$ equal to $2812 \mathrm{~Pa})$.

Tensile properties were measured in a TA.XT plus Texture Analyzer (Stable Microsystem Ltd., Godalming, UK) with a $30 \mathrm{~kg}$ load cell, controlled by Exponent software. The measurements were performed following recommended testing conditions from ASTM Standard Method D 882 in triplicate at $23 \pm 2{ }^{\circ} \mathrm{C}$ and $50 \% \pm 5 \%$ relative humidity. Films strips $50 \mathrm{~mm}$ length and $15 \mathrm{~mm}$ width were tested. The initial grip separation was set at $30 \mathrm{~mm}$ and the crosshead speed was set at $5 \mathrm{~mm} \cdot \mathrm{min}^{-1}$. Tensile strength (TS) was expressed in MPa and calculated by dividing the maximum load $(\mathrm{N})$ by the initial crosssectional area $\left(\mathrm{m}^{2}\right)$ of the test specimen. Elongation at break $(\% \mathrm{E})$ was calculated as the ratio of the final length at the point of sample rupture to the initial length of the specimen $(30 \mathrm{~mm})$ and expressed as a percentage.

\section{Results and Discussion}

\subsection{Deacetylation Degree (DD)}

The $\mathrm{DD}$, defined as the molar fraction of $\mathrm{N}$-acetylglucosamine units in the $\mathrm{CH}$ chain, is known to influence the activity of $\mathrm{CH}$ in several ways. It influences the physical, chemical and biological properties of $\mathrm{CH}$ and therefore is an important parameter for its processability into films or coatings and for the final performance. It is important to refer any results on performance of $\mathrm{CH}$-based materials to the $\mathrm{DD}$ of the $\mathrm{CH}$ samples used. The $\mathrm{CH}$ tested showed an average DD of $87.18 \% \pm 3.44 \%$, which is accordance with what is reported by the supplier (declared a value of deacetylation degree between 75-85\%), if differences between methods of determination are taken into consideration [30].

The higher the DD, the higher efficiency in inhibitory effect on bacteria and fungi has been reported, although the effect depends not only on the specific microorganism, but also on other factors such as the molecular weight and the $\mathrm{pH}$. The effect of DD was found to be more significant against Gram-negative bacteria (E. coli and C. jejuni) than against Gram-positive (L. monocytogenes) which is related to electrostatic mechanisms involving the interaction between negative bacterial cell wall and positively charged chitosan due to protonation of the $-\mathrm{NH}_{2}$ groups [32]. From the point-of view of the end-of life of the material and packages made of it, DD also influences the biodegradability. Higher DD yields slower biodegradation rates [33]. 


\subsection{Oleuropein Content in the OLE}

The result for the oleuropein content in the OLE tested was 12.7\% $\pm 0.2 \%$ (average of two replicates), which is ca $15 \%$ lower than the nominal labelled by the supplier. It is known that oleuropein is the most representative polyphenolic constituent of olive leaves and its concentration depends on factors inherent to the plant and to the process conditions used to produce the extracts. Values have been reported in the range of $6 \%$ to $9 \%$ and higher (dry basis) [34], but often values are reported in fresh weigh basis making comparison difficult.

\subsection{Anti-Microbial Effect of OLE in L. monocytogenes, E. coli and C. jejuni}

Many studies confirmed some antimicrobial activity of olive leaf extract against different microorganisms with interest for food products quality and safety, such as L. monocytogenes [35], E. coli [35-37], and Salmonella enteriditis [35], Pseudomonas aeruginosa [36] and Staphylococcus aureus [36-39]. The effect on the growth rates was found to depend on the extract concentration for the case of S. aureus and E. coli [37]. However, most of these works did not focus on the activity of OLE after being incorporated in a packaging film, which was targeted in the present work.

The effect of OLE incorporated at different concentrations in chitosan films is following presented in Figures 1-3. The growth curves of the target microorganisms were previously determined to allow for planning the experiments with the films and define the sampling times to monitor the $\mathrm{OD}_{600}$ measurements (Supplementary Materials, Figures S1-S3). This method was selected because is quick and inexpensive as it permits readings of high number of samples obtained at different conditions, microorganisms and replicates at the same time, and the testing volume needed is very low $(200 \mu \mathrm{L})$. It is used to assess bacteria cell growth inhibition, during their culture in liquid media, monitoring the solution $\mathrm{OD}_{600}$ relying on the effect of cell lysis in the solution turbidity.

Room temperature was included in the studies because published results at this temperature, which may represent a potential slight abuse of storage of products that are intended to be stored under refrigeration, are scarce. Furthermore, at lower temperatures (refrigeration) the time required to run the experiments would have been much higher.

Figures 1-3 show the target microorganisms growth curves, at both temperatures tested for each microorganism, in the presence of chitosan $2 \%$ film, chitosan $2 \%+$ OLE films (extract concentration of $10 \%, 20 \%$ and $30 \%$ ) and also the positive control (no active films). In general, both chitosan $2 \%$ and chitosan $2 \%+$ OLE films inhibited bacterial growth relative to the positive controls and in some cases the films extended the lag phase, as following described.

Results for L. monocytogenes (Figure 1A,B) show that all active films had stronger antibacterial effect at room temperature than at $37^{\circ} \mathrm{C}$. Indeed, at room temperature the microorganism in contact with films showed low level of growth, with minor differences between chitosan films and films with different OLE concentrations. At $37^{\circ} \mathrm{C}$, chitosan $2 \%$ film inhibit the growth of L. monocytogenes up to $24 \mathrm{~h}$. The films that contain OLE at different concentrations allow the growth of the microorganism but, in comparison with the control, with a longer lag phase, particularly evident in the sample with CH $2 \%+$ OLE $10 \%$. However, the microorganism seems to be able to reach the same growth level as in the control, despite the antimicrobial substances' presence. These results show that the inhibitory effect of the films with higher concentration (20\% and 30\%) of OLE is lower than that of the films of chitosan only or of chitosan incorporated with $10 \%$ OLE. This seems to indicate that the incorporation of OLE in the chitosan structure has a negative impact on the intrinsic activity of chitosan itself. This can possibly be explained by OLE particles dispersed in the matrix affecting the transfer through the $\mathrm{CH}$ matrix of chemical species involved in its inhibitory mechanisms. Previous works have shown that incorporation of OLE in PLA films affected its water permeability [40]. The diffusion of organic acids incorporated in $\mathrm{CH}$ films were also found to be affected by the presence of eugenol or cinnemaldehyde in the matrix [41]. Works with different essential oils (EO) have been reported showing successful incorporation in the $\mathrm{CH}$ matrix with improvements of the 
intrinsic antibacterial properties of chitosan [16,17]. However, the dispersion of EO in the $\mathrm{CH}$ matrix differs from the present case where OLE particles were dispersed, and in fact the EO may act as plasticiser thus facilitating the mass transport through the $\mathrm{CH}$ matrix, thus having an opposite effect. The incorporation of OLE in the chitosan matrix seems to decrease the antimicrobial effect of chitosan. If this effect is related to changes in the chitosan matrix affecting transport properties, than it could be expected that the decreasing effect is higher for films with higher OLE concentration as shown in the results. This may be worthy of further verification.


Figure 1. Growth curves of Listeria monocytogenes at room temperature (A) and at $37^{\circ} \mathrm{C}(\mathbf{B})$ : $\bullet$ no films; $\triangle \mathrm{CH} 2 \%$ films; $\triangle \mathrm{CH} 2 \%+$ OLE $10 \%$ films; $\mathrm{CH} 2 \%+$ OLE $20 \%$ films; $-\mathrm{CH} 2 \%+$ OLE $30 \%$ films.

OLE films did not exhibit significant antimicrobial effect against $E$. coli. The growth curves of E. coli, at room temperature and at $37^{\circ} \mathrm{C}$, when in contact with the OLE films seem to be not affected by OLE concentration (Figure $2 \mathrm{~A}, \mathrm{~B}$ ). The recorded values of $\mathrm{OD}_{600}$ are lower when the microorganism is in contact with OLE films but a similar growth behaviour to the control is seen at the two temperatures. The films with chitosan $2 \%$ and no OLE added showed a complete inhibition of E. coli at room temperature. However, at $37^{\circ} \mathrm{C}$, the delay in growth was observed for a period of ca $5 \mathrm{~h}$, after which the bacteria reproduced, but less than that the control. 

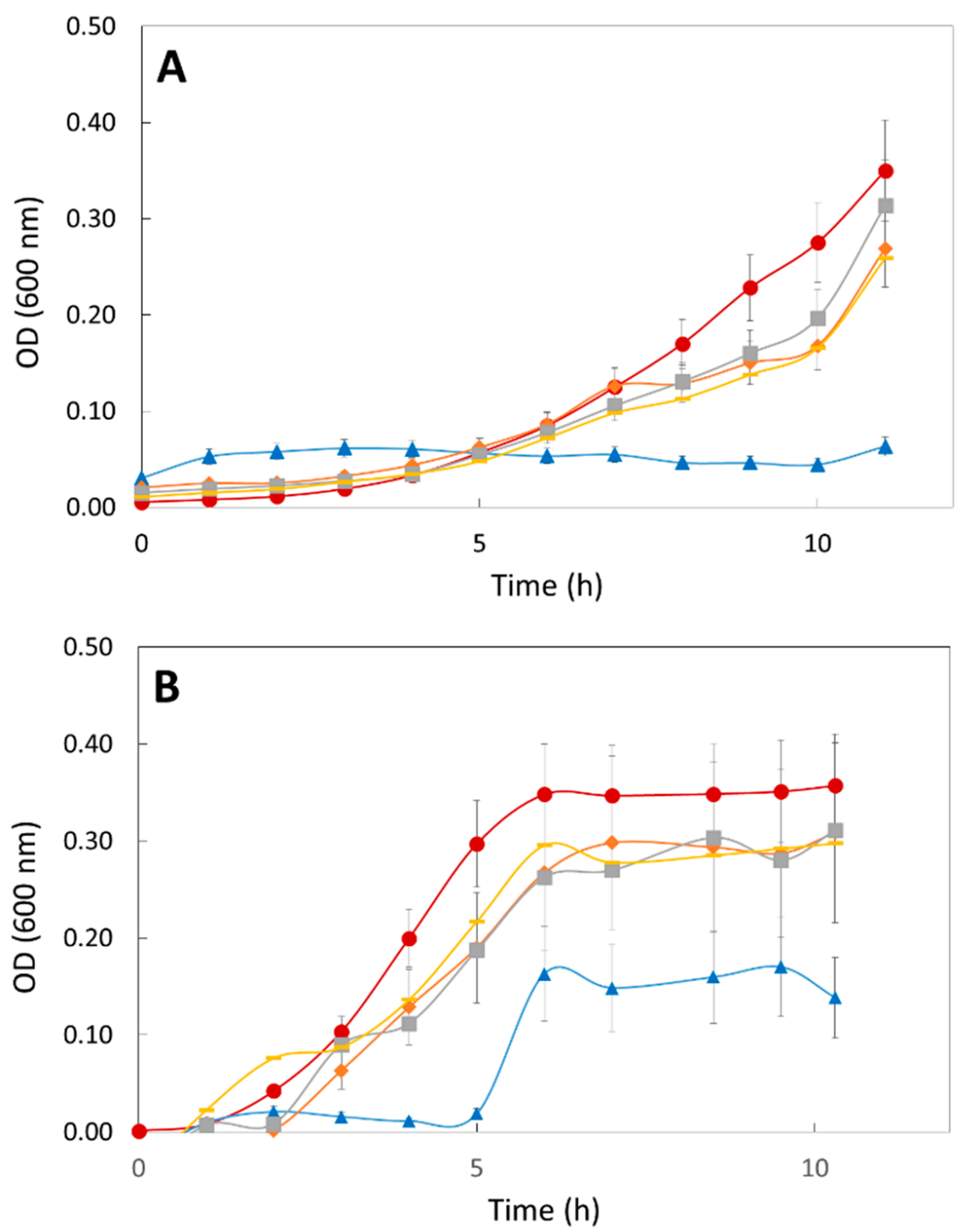

Figure 2. Growth curves of Escherichia coli at room temperature (A) and at $37{ }^{\circ} \mathrm{C}(\mathbf{B})$ : • no films; $\triangle \mathrm{CH} 2 \%$ films; $\triangle \mathrm{CH} 2 \%$ + OLE 10\% films; $-\mathrm{CH} 2 \%+$ OLE $20 \%$ films; $-\mathrm{CH} 2 \%+$ OLE 30\% films.

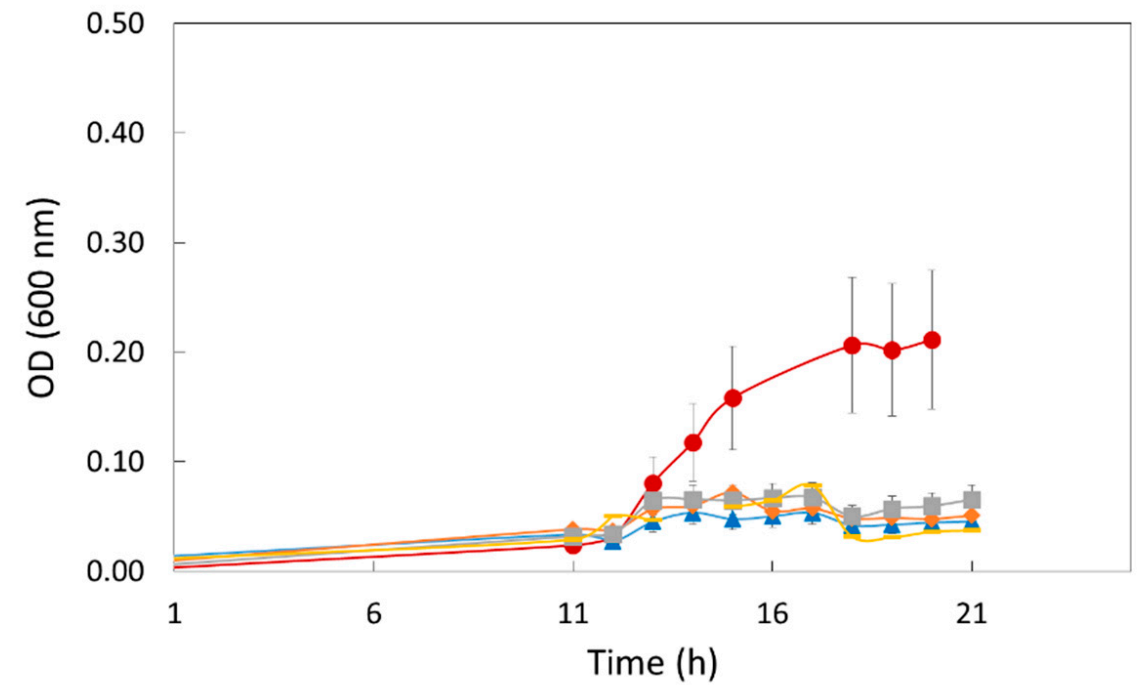

Figure 3. Growth curve of Campylobacter spp. at $41.5^{\circ} \mathrm{C}: \bullet$ no films; $\Delta \mathrm{CH} 2 \%$ films; $\triangleleft \mathrm{CH} 2 \%+\mathrm{OLE}$ $10 \%$ films; $-\mathrm{CH} 2 \%$ + OLE $20 \%$ films; - CH 2\% + OLE 30\% films. 
The effect of antimicrobial films on Campylobacter spp. was only evaluated at $41.5^{\circ} \mathrm{C}$. The films with chitosan + OLE seem to have a significant effect on the growth of $C$. jejuni. It was not observed growth at all OLE concentrations until the end of the experiment (Figure 3). In the sample with chitosan $2 \%$ film, this effect was also observed for shorter contact times (up to ca $20 \mathrm{~h}$ ). However, the $\mathrm{OD}_{600}$ value was similar to the control after $40 \mathrm{~h}$ of contact (data not showed). Therefore, in this case, results seem to indicate that the OLE incorporation improves the $\mathrm{CH}$ antimicrobial performance and the films are able to inhibit the growth of $C$. jejuni at all concentrations tested.

Overall these results are consistent with findings from other authors that concluded that OLE has not a broad-spectrum of antimicrobial activity, but shows appreciable activity against $C$. jejuni with a minimum inhibitory concentration in the range of $0.3 \%-2.5 \%$ [42].

\subsection{In Situ Test Using Chicken Pieces}

Following the promising results with the $\mathrm{CH}+$ OLE films, an in situ test was performed where sterile agar with OLE at $2 \%(w / w)$ was brought in contact with inoculated chicken pieces. The concentration of $2 \%$ OLE was selected because it is four times higher than the minimum obtained in prior microbiological tests (not reported here) and still does not impart a strong olive smell. Sterile agar was chosen to simulate the packaging material because it is a non-nutritive, neutral culture medium. Chitosan films were not used in this test to allow for concluding on the specific effect of OLE.

The contamination step of the chicken pieces resulted in a number of Campylobacter spp. of $1.1 \times 10^{8} \mathrm{CFU} \mathrm{g}^{-1}$. When in contact for $24 \mathrm{~h}$ with the OLE containing agar and stored at $41.5^{\circ} \mathrm{C}$, the Campylobacter spp. count in meat was $<1.0 \times 10 \mathrm{CFU} \cdot \mathrm{g}^{-1}$, while in control agar without OLE the number was $8.5 \times 10^{7} \mathrm{CFU} \cdot \mathrm{g}^{-1}$. Therefore, a 6-log reduction was achieved in the meat stored at $41.5^{\circ} \mathrm{C}$. However, when the meat was removed from the contact with OLE containing agar, some growth was observed upon incubation for $24 \mathrm{~h}$ at $41.5^{\circ} \mathrm{C}$ under microaerophilic conditions in non-OLE containing agar. Therefore, these results indicate that Campylobacter spp. growth is reduced but some cells remain viable. This may mean that the OLE affects either the number of viable bacteria (by killing some) or affects the cells metabolism (cells viable but not culturable).

In the meat stored at $4{ }^{\circ} \mathrm{C}$ the results show that the concentration of bacteria is high $\left(>1000 \mathrm{CFU} \cdot \mathrm{g}^{-1}\right)$ thus indicting that the potential reduction is not at the same level of that at $41.5^{\circ} \mathrm{C}$. These results should be confirmed for the other microorganisms.

\subsection{Antioxidant Activity of the Films}

The results for the antioxidant activity expressed as AAEAC are presented in Table 1. There is an increase in the AAEAC with the increase of concentration of OLE incorporated in the $\mathrm{CH}$ film, ranging from $0.04 \mathrm{AA}$ eq. $\mathrm{g} / \mathrm{L}$ for the film with $10 \% w / w$ OLE to 0.15 AA eq. $\mathrm{g} / \mathrm{L}$ for the film with $30 \% w / w$ OLE. These results are in agreement with results obtained when olive pomace was incorporated into $\mathrm{CH}$ films [43] and when OLE was immobilised in an adhesive layer to build a multi-layer polyethylene film and a paper/polyethylene film [44].

Table 1. Antioxidant activity expressed in ascorbic acid eq. $\left(\mathrm{g} \mathrm{L}^{-1}\right)$. Average \pm standard deviation.

\begin{tabular}{cc}
\hline Sample & AAEAC, g/L \\
\hline OLE powder & $0.25 \pm 0.01$ \\
CH 2\% film & $0.01 \pm 0.01$ \\
OLE film (10\%) & $0.04 \pm 0.00$ \\
OLE film (20\%) & $0.08 \pm 0.01$ \\
OLE film (30\%) & $0.15 \pm 0.01$ \\
\hline
\end{tabular}

Although oleuropein is the most abundant compound in OLE, the antioxidant effect is mostly provided by other molecules, namely by hydroxytyrosol, luteolin, diosmetin, rutin 
and catechin. These flavonols, flavans-3-ols and flavones with catechol structures are the most efficient phenolic compound quenchers for the $\mathrm{ABTS}^{*+}$ radical cation [45].

The OLE powder sample presented the highest average value of $0.26 \mathrm{~g} \cdot \mathrm{L}^{-1}$ of AAEAC. This value is higher than the one recorded for the film $\mathrm{CH}$ with $30 \%$ of OLE, in spite of the similar amount of OLE present in both samples. This effect is probably due to the lower availability of OLE bioactive compounds when incorporated in the $\mathrm{CH}$ film than when is added to the testing solution as a powder.

Results of the present work also highlight that the chitosan film has much lower antioxidant activity when compared to the films with OLE incorporated. There are numerous studies addressing antioxidant activity of chitosan [46,47]. Antioxidant properties of chitosan have been attributed to its free-radical scavenging ability and chelation of metal ions [48] and to depend on the degree of deacetylation. However, the enhancement of antioxidant properties through combination of chitosan with active compounds (mostly essential oils and extracts but also lignin and graphene oxide, for example) is referred [45] and that can also be concluded from present results.

\subsection{Physical Characteristics of the Films}

The visual appearance of the film can be seen in Figure 4. Films are transparent with a yellowish taint increasing with the concentration of the OLE, and showing some insoluble particles.
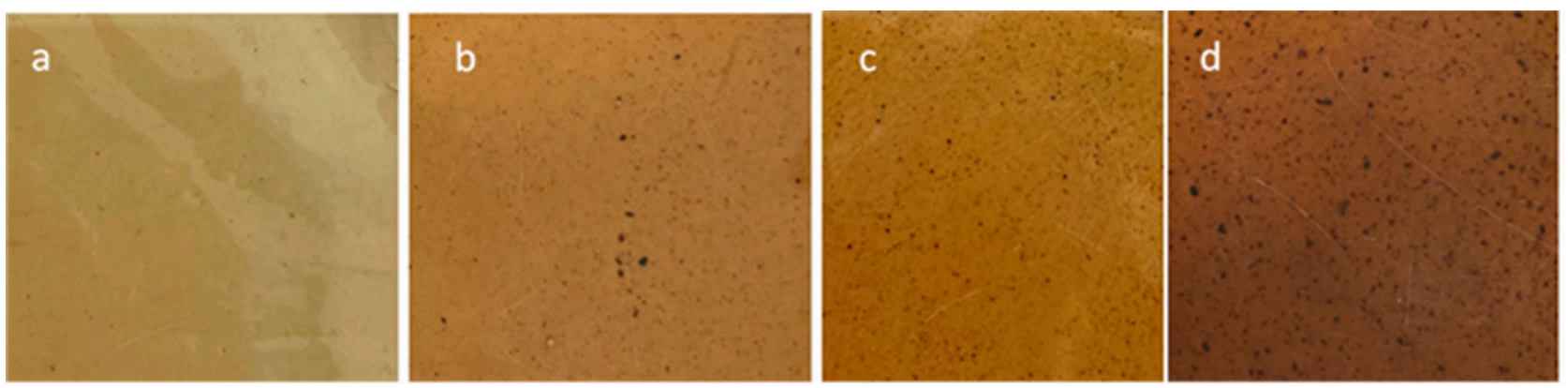

Figure 4. Visual appearance of the films (40× magnification) of (a) $\mathrm{CH} 2 \%$ film; (b) $\mathrm{CH} 2 \%+\mathrm{OLE} 10 \%$ film; (c) $\mathrm{CH} 2 \%$ + OLE $20 \%$ films; (d) $\mathrm{CH} 2 \%+$ OLE $30 \%$ film.

Figure 5 presents the values for the solubility of the films when tested with different simulant solutions at room temperature. It is known that chitosan based films have high solubility due to water binding capacity of functional groups and glycerol added as plasticiser. The solubility of the films with OLE was higher than that of the film of chitosan only, for all food simulants $(p<0.05)$. There was a trend for the films solubility to increase with the increase of the OLE content in the film, particularly for water and for acid simulant (Figure 5). However, the differences between films with 10\%, 20\% or 30\% OLE were not statistically significant $(p>0.05)$ in the case of ethanol solutions. The solubility of chitosan film ranged from $21 \%$ to $26 \%$ in water and in the ethanol solutions, while in acetic acid solution the solubility was much lower-12\%. All films with OLE also exhibited lower solubility in acetic acid solution as compared with water or with ethanol simulants. For application as packaging, or more generically as a food contact layer (for example as pad), materials with low solubility are required, especially in the case of high moist foods. If the films are to be used in fresh meat or processed meat products such as ham and sausages, water is the simulant most relevant (besides a fatty simulant that was not tested). For preserved meat, in an aqueous medium, the simulants acetic acid and ethanol $50 \%$ would be the ones prescribed for testing food contact materials. However, it can be recognised that the conditions of test (immersion in liquid simulants) are more aggressive than the contact with the moist solid food. 


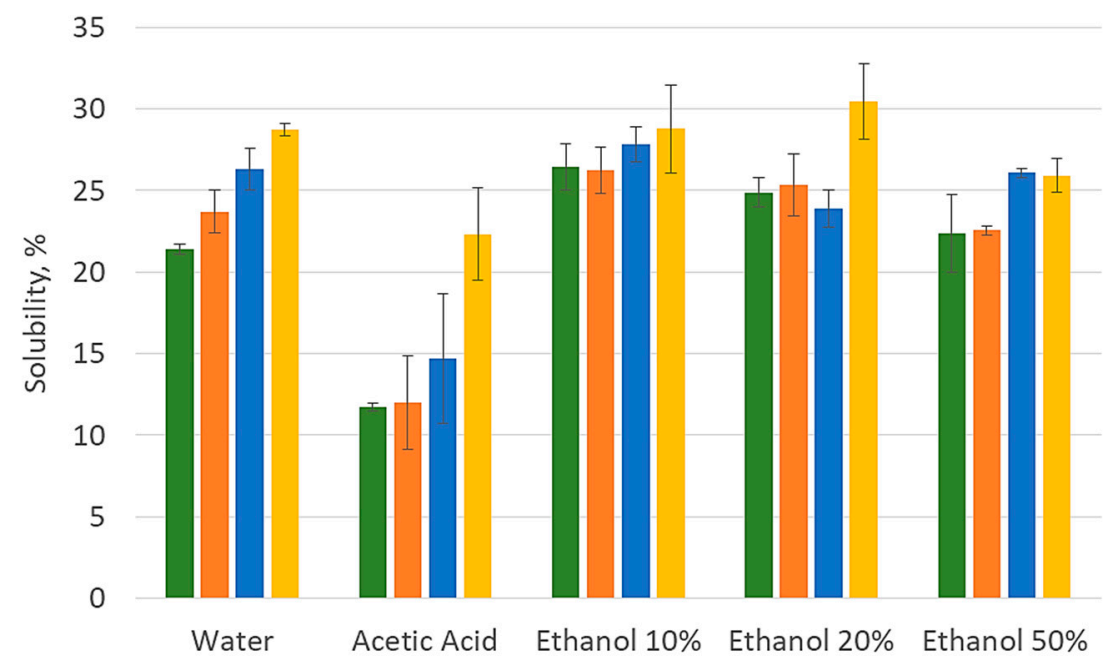

Figure 5. Solubility of films in food simulants ( $-\mathrm{CH} 2 \%$ films; $\square-\mathrm{CH} 2 \%+\mathrm{OLE} 10 \%$ films; $\square-\mathrm{CH}$ $2 \%+$ OLE 20\%;-CH $2 \%+$ OLE $30 \%$ ).

The moisture permeability of a film is one of the most important properties for many packaging applications. The relative poor barrier of most bio-based polymers is well known. The permeability of the chitosan films and chitosan combined with OLE is presented in Table 2. The permeability of chitosan film at $23{ }^{\circ} \mathrm{C}$ and $50 \%$ relative humidity was $4.92 \times 10^{-11} \mathrm{~g} \cdot \mathrm{Pa}^{-1} \cdot \mathrm{s}^{-1} \cdot \mathrm{m}^{-1}$ in line with values found in the literature $[43,49]$. The incorporation of OLE decreased the permeability of the chitosan films. This may be explained by the hydrophobic nature of the OLE, as recently shown on geltain films loaded with cinnamon essential oil [50]. As shown in Table 2, films with $10 \%$ OLE had a permeability $20 \%$ lower than the chitosan, while for films with $20 \%$ OLE the decrease was ca $40 \%$. The difference between the permeability values for films with $20 \%$ and $30 \%$ OLE was not statistically significant $(p>0.05)$.

Table 2. Moisture permeability of films at $23{ }^{\circ} \mathrm{C}$ and $50 \%$ relative humidity. Tensile strength and elongation at break. Results are expressed as average \pm standard deviation.

\begin{tabular}{|c|c|c|c|}
\hline Sample & $\mathrm{WVP}\left(\mathrm{g} \cdot \mathrm{Pa}^{-1} \cdot \mathrm{s}^{-1} \cdot \mathrm{m}^{-1}\right)$ & TS (MPa) & $\mathrm{E}(\%)$ \\
\hline $\mathrm{CH} 2 \%$ film & $(4.92 \pm 0.12) \times 10^{-11}$ & $17.02 \pm 2.27$ & $4.34 \pm 1.25$ \\
\hline OLE film (10\%) & $(3.97 \pm 0.32) \times 10^{-11}$ & $25.13 \pm 1.62$ & $18.7 \pm 1.33$ \\
\hline OLE film $(20 \%)$ & $(2.90 \pm 0.20) \times 10^{-11}$ & $18.12 \pm 3.45$ & $12.4 \pm 3.04$ \\
\hline OLE film (30\%) & $(2.72 \pm 0.30) \times 10^{-11}$ & $21.97 \pm 3.14$ & $11.6 \pm 0.63$ \\
\hline
\end{tabular}

Several factors affect the mechanical properties of the films such as: the chitosan composition and source, presence and content of a plasticizer, film preparation and storage. The results for the mechanical properties are shown in Table 2. Results were affected by the non-homogeneous structure of the films caused by the presence of insoluble particles. The tensile strength was not significantly affected by the OLE incorporation while elongation at break increased with OLE incorporation, but the effect of increasing the concentration was inconclusive due to variability between replicas. The results for TS and \%E were in the same range of values found in literature for chitosan based films $[43,49]$. The tensile strength values were comparable to values of high density polyethylene but lower than values of polypropylene, for example, while the elongation was much lower than that of traditional films.

\section{Conclusions}

Results indicate that the $\mathrm{CH}+$ OLE films have substantial antimicrobial activity against L. monocytogenes and C. jejuni. The inhibition is not so evident in the case of E. coli. However, 
the OLE seems not to improve the intrinsic antimicrobial properties of the chitosan itself. On the contrary, it seems that the inclusion of OLE in chitosan films refrain to some extend the chitosan effect.

The antimicrobial effect of the $\mathrm{CH}+\mathrm{OLE}$ films against L. monocytogenes was more evident at room temperature than at $37^{\circ} \mathrm{C}$. Therefore, results suggest that $\mathrm{CH}+\mathrm{OLE}$ may play an important role in inhibiting microorganisms capable of growing in food at refrigerated temperatures. The antimicrobial effect of the $\mathrm{CH}+$ OLE films against E. coli was lower than that of the $\mathrm{CH}$ only films, which indicates that for this microorganism OLE incorporated may interfere with the active mechanism of the chitosan matrix. This effect was also observed for the L. monocytogenes in contact with the films at the highest temperature.

Results of OLE against C. jejuni present in chicken pieces show that OLE per se has an inhibitory effect but not bactericidal, at $41.5^{\circ} \mathrm{C}$.

The films with OLE incorporated exhibited an interesting antioxidant activity. Chitosan films do not show relevant antioxidant activity. Therefore, for practical applications, the relevance relies on the combination of the two active compounds, chitosan providing antimicrobial and OLE providing antioxidant properties.

For food packaging applications, especially when the contact with food is envisaged, physical properties of the active materials are also important. The solubility of the materials in contact with the food or food simulants is a measure of its inertness. The incorporation of OLE increased the solubility values of the chitosan films ca $10 \%$ in water and acetic acid solution. The effect of OLE was lower for films in contact with ethanolic simulants. The water vapor permeability of the chitosan films decreased with the increase of OLE content in the film, possibly due to the hydrophobic nature of the OLE. The mechanical properties were evaluated through the parameters tensile strength and elongation, with results comparable to polyolefins in the first case but lower elongation values.

Overall, the results obtained suggest that the use of OLE incorporated in chitosan films can be a promising approach for the packaging industry to ensure the microbiological safety of food and prevent earlier oxidative degradation.

Supplementary Materials: The following are available online at https:/ / www.mdpi.com/article/ 10.3390 /coatings11111339/s1, Figure S1: Growth curves at room temperature and at $37{ }^{\circ} \mathrm{C}$ for Listeria monocytogenes, Figure S2: Growth curves at room temperature and at $37^{\circ} \mathrm{C}$ for Escherichia coli, Figure S3: Growth curves at room temperature and at $42.5^{\circ} \mathrm{C}$ for Campylobacter spp.

Author Contributions: Conceptualization, F.P. and S.F.; methodology, C.M. and F.P.; validation, C.M.; formal analysis, E.M., A.R.M.; investigation, E.M., I.C.e.O. and C.M.; resources, P.T., F.P.; writingoriginal draft preparation, E.M., I.C.e.O. and C.R.; writing-review and editing, P.T., F.P. and S.F.; supervision, C.M. and F.P.; funding acquisition, P.T. and S.F. All authors have read and agreed to the published version of the manuscript.

Funding: This research was funded by PDR 2020, Portugal 2020 and the EU GRUPO OPERACIONAL ID 228, CAMPYFREE: Estratégias de controlo de Campylobacter em carne de aves e produtos cárneos derivados, PDR2020-1.0.1-FEADER-PDR2020-101-031254.

Institutional Review Board Statement: Not applicable.

Informed Consent Statement: Not applicable.

Data Availability Statement: Not applicable.

Acknowledgments: The authors thank the scientific collaboration under the FCT Portuguese project UIDB/50016/2020.

Conflicts of Interest: The authors declare no conflict of interest.

\section{References}

1. Scherhaufer, S.; Moates, G.; Hartikainen, H.; Waldron, K.; Obersteiner, G. Environmental impacts of food waste in europe. Waste Manag. 2018, 77, 98-113. [CrossRef] [PubMed]

2. Mitelut, A.C.; Tănase, E.E.; Popa, V.I.; Popa, M.E. Sustainable alternative for food packaging: Chitosan biopolymer-A review. AgroLife Sci. J. 2015, 4, 52-61. 
3. Silva, J.; Leite, D.; Fernandes, M.; Mena, C.; Gibbs, P.A.; Teixeira, P. Campylobacter spp. as a foodborne pathogen: A review. Front. Microbiol. 2011, 2, 200. [CrossRef]

4. Hoffmann, S.; Scallan, E. Epidemiology, Cost, and Risk Analysis of Foodborne Disease (Chapter 2) in Foodborne Diseases, 3rd ed.; Christine, E.R.D., Tim, A., Richard, A.S., Dean, O.C., Hans, P.R., Eds.; Academic Press: Cambridge, MA, USA, 2017 ; pp. 31-63.

5. Volpe, S.; Cavella, S.; Torrieri, E. Biopolymer coatings as alternative to modified atmosphere packaging for shelf life extension of minimally processed apples. Coatings 2019, 9, 569. [CrossRef]

6. Shen, Z.; Kamdem, D.P. Development and characterization of biodegradable chitosan films containing two essential oils. Int. J. Biol. Macr. 2015, 74, 289-296. [CrossRef]

7. European Commission. Commission Regulation (EU), No. 10/2011 of 14 January 2011. Off. J. Eur. Union 2011, 54, 1-89.

8. Ashrafi, A.; Jokar, M.; Mohammadi Nafchi, A. Preparation and characterization of biocomposite film based on chitosan and kombucha tea as active food packaging. Int. J. Biol. Macr. 2018, 108, 444-454. [CrossRef] [PubMed]

9. Petrou, S.; Tsiraki, M.; Giatrakou, V.; Savvaidis, I.N. Chitosan dipping or oregano oil treatments, singly or combined on modified atmosphere packaged chicken breast meat. Int. J. Food Microbiol. 2012, 156, 264-271. [CrossRef]

10. Lozano-Navarro, J.I.; Díaz-Zavala, N.P.; Velasco-Santos, C.; Melo-Banda, J.A.; Páramo-García, U.; Paraguay-Delgado, F.; GarcíaAlamilla, R.; Martínez-Hernández, A.L.; Zapién-Castillo, S. Chitosan-starch films with natural extracts: Physical, chemical, morphological and thermal properties. Materials 2018, 11, 120. [CrossRef] [PubMed]

11. Treviño-Garza, M.Z.; Correa-Cerón, R.C.; Ortiz-Lechuga, E.G.; Solís-Arévalo, K.K.; Castillo-Hernández, S.L.; Gallardo-Rivera, C.T.; Arévalo Niño, K. Effect of linseed (Linum usitatissimum) mucilage and chitosan edible coatings on quality and shelf-life of fresh-cut cantaloupe (Cucumis melo). Coatings 2019, 9, 368. [CrossRef]

12. Hosseinnejad, M.; Jafari, S.M. Evaluation of different factors affecting antimicrobial properties of chitosan. Int. J. Biol. Macr. 2016, 85, 467-475. [CrossRef]

13. Kumar, S.; Mukherjee, A.; Dutta, J. Chitosan based nanocomposite films and coatings: Emerging antimicrobial food packaging alternatives. Trends Food Sci. Technol. 2020, 97, 196-209. [CrossRef]

14. Abd El-Hack, M.E.; El-Saadony, M.T.; Shafi, M.E.; Zabermawi, N.M.; Arif, M.; Batiha, G.E.; Khafaga, A.F.; Abd El-Hakim, Y.M.; Al-Sagheer, A.A. Antimicrobial and antioxidant properties of chitosan and its derivatives and their applications: A review. Int. J. Biol. Macr. 2020, 164, 2726-2744. [CrossRef] [PubMed]

15. Coma, V.; Deschamps, A.; Martial-Gros, A. Bioactive packaging materials from edible chitosan polymer-Antimicrobial activity assessment on dairy-related contaminants. J. Food Sci. 2003, 68, 2788-2792. [CrossRef]

16. Yuan, G.; Chen, X.; Li, D. Chitosan films and coatings containing essential oils: The antioxidant and antimicrobial activity, and application in food systems. Food Res. Int. 2016, 89, 117-128. [CrossRef]

17. Siripatrawan, U.; Harte, B.R. Physical properties and antioxidant activity of an active film from chitosan incorporated with green tea extract. Food Hydrocoll. 2010, 24, 770-775. [CrossRef]

18. Lekjing, S. A chitosan-based coating with or without clove oil extends the shelf life of cooked pork sausages in refrigerated storage. Meat Sci. 2016, 111, 192-197. [CrossRef]

19. Souza, V.G.L.; Pires, J.R.A.; Rodrigues, C.; Freitas Rodrigues, P.; Lopes, A.; Silva, R.J.; Caldeira, J.; Duarte, M.P.; Braz Fernandes, F.; Coelhoso, I.M.; et al. Physical and morphological characterization of chitosan/montmorillonite films incorporated with ginger essential oil. Coatings 2019, 9, 700. [CrossRef]

20. Zhou, Y.; Xu, T.; Zhang, Y.; Zhang, C.; Lu, Z.; Lu, F.; Zhao, H. Effect of tea polyphenols on curdlan/chitosan blending film properties and its application to chilled meat preservation. Coatings 2019, 9, 262. [CrossRef]

21. Li, N.; Liu, W.; Shei, Y.; Mei, J.; Xie, J. Coating effects of $\varepsilon$-polylysine and rosmarinic acid combined with chitosan on the storage quality of fresh half-smooth tongue sole (Cynoglossus semilaevis Günther) fillets. Coatings 2019, 9, 273. [CrossRef]

22. Yuan, G.; Lv, H.; Tang, W.; Zhang, X.; Sun, H. Effect of chitosan coating combined with pomegranate peel extract on the quality of Pacific white shrimp during iced storage. Food Control 2016, 59, 818-823. [CrossRef]

23. Li, C.; Pei, J.; Zhu, S.; Song, Y.; Xiong, X.; Xue, F. Development of chitosan/peptide films: Physical, antibacterial and antioxidant properties. Coatings 2020, 10, 1193. [CrossRef]

24. Kiritsakis, K.; Kontominas, M.G.; Kontogiorgis, C.; Hadjipavlou-Litina, D.; Moustakas, A.; Kiritsakis, A. Composition and antioxidant activity of olive leaf extracts from Greek Olive cultivars. J. Am. Oil Chem. Soc. 2010, 87, 369-376. [CrossRef]

25. Dua, S.; Bhat, Z.F.; Kumar, S. Effect of oleuropein on the oxidative stability and storage quality of Tabaq-Maz, fried mutton ribs. Food Biosci. 2015, 12, 84-92. [CrossRef]

26. Ahmed, A.M.; Rabii, N.S.; Garbaj, A.M.; Abolghait, S.K. Antibacterial effect of olive (Olea europaea L.) leaves extract in raw peeled undeveined shrimp (Penaeus semisulcatus). Int. J. Vet. Sci. Med. 2014, 2, 53-56. [CrossRef]

27. Yingyuad, S.; Ruamsin, S.; Reekprkhon, D.; Suwassa, P.; Siripatrawan, U. Effect of chitosan coating and vacuum packaging on the quality of refrigerated grilled pork. Packag. Technol. Sci. 2006, 19, 149-157. [CrossRef]

28. Peng, Y.; Li, Y. Combined effects of two kinds of essential oils on physical, mechanical and structural properties of chitosan films. Food Hydrocoll. 2014, 36, 287-293. [CrossRef]

29. Szymański, M.; Witkowska-Banaszczak, E.; Matławska, I.; Szymański, A. Determination of oleuropein in herbal preparation and Olea europaea L. extracts by HPLC. Ars Sep. Acta 2012, 9-10, 55-63.

30. Czechowska-Biskup, R.; Jarosińska, D.; Rokita, B.; Ulański, P.; Rosiak, J.M. Determination of degree of deacetylation of chitosanComparision of methods. Prog. Chem. Appl. Chitin Deriv. 2012, 17, 5-20. 
31. Ozgen, M.; Reese, R.N.; Tulio, A.Z.; Scheerens, J.C.; Miller, A.R. Modified 2,2-azino-bis-3 ethylbenzothiazoline-6-sulfonic acid (ABTS) method to measure antioxidant capacity of selected small fruits and comparison to ferric reducing antioxidant power (FRAP) and 2,2'-diphenyl-1- picrylhydrazyl (DPPH) methods. J. Agric. Food Chem. 2006, 54, 1151-1157. [CrossRef]

32. Younes, Y.; Sellimi, S.; Rinaudo, M.; Jellouli, K.; Nasri, M. Influence of acetylation degree and molecular weight of homogeneous chitosans on antibacterial and antifungal activities. Int. J. Food Microbiol. 2014, 185, 57-63. [CrossRef]

33. Croisier, F.; Jerome, C. Chitosan based biomaterials for tissue engineering. Eur. Polym. J. 2013, 49, 780-792. [CrossRef]

34. Romani, A.; Mulas, S.; Heimler, D. Polyphenols and secoiridoids in raw material (Olea europaea L. leaves) and commercial food supplements. Eur. Food Res. Technol. 2017, 243, 429-435. [CrossRef]

35. Liu, Y.; McKeever, L.C.; Malik, N.S.A. Assessment of the antimicrobial activity of olive leaf extract against foodborne bacterial pathogens. Front. Microbiol. 2017, 8, 113. [CrossRef] [PubMed]

36. Markin, D.; Duek, L.; Berdicevsky, I. In vitro antibacterial activity of olive leaves. Mycoses 2003, 46, 132-136. [CrossRef] [PubMed]

37. Pereira, A.P.; Ferreira, I.C.F.R.; Marcelino, F.; Valentao, P.; Andrade, P.B.; Seabra, R.; Estevinho, L.; Bento, A.; Pereira, J.A. Phenolic compounds and antibacterial activity of olive (Olea europaea L. Cv. Cobrancosa) leaves. Molecules 2007, 12, 1153-1162. [CrossRef] [PubMed]

38. Nassrullah Malik, S. Antibacterial activity of olive (Olea europaea) leaves and arugula (Eruca sativa) seeds extract. Int. J. Pharmacogn. Phytochem. Res. 2015, 7, 307-310.

39. Azizollahi Aliabadi, M.; Kazemi Darsanaki, R.; Laleh Rokhi, M.; Nourbakhsh, M.; Raeisi, G. Antimicrobial activity of olive leaf aqueous extract. Ann. Biol. Res. 2012, 3, 4189-4191.

40. Erdohan, Z.O.; Çam, B.; Turhan, K.N. Characterization of antimicrobial polylactic acid based films. J. Food Eng. 2013, 119, 308-315. [CrossRef]

41. Ouattara, B.; Simard, R.E.; Piette, G.; Bégin, A.; Holley, R.A. Diffusion of acetic and propionic acids from chitosan-based antimicrobial packaging films. J. Food Sci. 2000, 65, 768-773. [CrossRef]

42. Sudjana, A.N.; D’Orazio, C.; Ryan, V.; Rasool, N.; Ng, J.; Islam, N.; Hammer, K.A. Antimicrobial activity of commercial Olea europaea (olive) leaf extract. Int. J. Antimicrob. Ag. 2009, 33, 461-463. [CrossRef] [PubMed]

43. Crizel, M.T.; Oliveira Rios, A.; Alves, V.; Bandarra, N.; Moldão-Martins, M.; Flôres, S.H. Active food packaging prepared with chitosan and olive pomace. Food Hydrocoll. 2018, 74, 139-150. [CrossRef]

44. Moudache, M.; Colon, M.; Nerín, C.; Zaidi, F. Phenolic content and antioxidant activity of olive by-products and antioxidant film containing olive leaf extract. Food Chem. 2016, 212, 521-527. [CrossRef]

45. Benavente-García, O.; Castillo, J.; Lorente, J.; Ortuño, A.; Del Rio, J.A. Antioxidant activity of phenolics extracted from Olea europaea L. leaves. Food Chem. 2000, 68, 457-462. [CrossRef]

46. Ngo, D.-H.; Kim, S.-K. Antioxidant effects of chitin, chitosan, and their derivatives. Mar. Carbohydr. Fundam. Appl. Part B 2014, 15-31. [CrossRef]

47. Xie, W.; Xu, P.; Liu, Q. Antioxidant activity of water-soluble chitosan derivatives. Bioorg. Med. Chem. Lett. 2001, 11, 1699-1701. [CrossRef]

48. Anraku, M.; Gebicki, J.M.; Iohara, D.; Tomida, H.; Uekama, K.; Maruyama, T. Antioxidant activities of chitosans and its derivatives in in vitro and in vivo studies. Carbohyd. Polym. 2018, 199, 141-149. [CrossRef]

49. Kurek, M.; Galus, S.; Debeaufort, F. Surface, mechanical and barrier properties of bio-based composite films based on chitosan and whey protein. Food Packag. Shelf Life 2014, 56-67. [CrossRef]

50. Razavi, M.S.; Golmohammadi, A.; Nematollahzadeh, A.; Rovera, C.; Farris, S. Fish gelatin-bacterial cellulose nanocrystals active films containing cinnamon essential oil nanocapsules. Food Biophys. 2021. [CrossRef] 